\title{
Aortoesophageal fistula resulting from aortic endograft migration
}

Ramiro Fernandez, MD, S. Chris Malaisrie, MD, Andrew Hoel, MD, and Ankit Bharat, MD

From the Department of Surgery, Northwestern University Feinberg School of Medicine, Chicago, Ill.

Disclosures: A.B. is supported by National Institutes of Health Grant HL125940. All other authors have nothing to disclose with regard to commercial support.

Received for publication March 16, 2017; revisions received April 5, 2017; accepted for publication April 22, 2017; available ahead of print June 26, 2017.

Address for reprints: Ankit Bharat, MD, Division of Thoracic Surgery, Northwestern University Feinberg School of Medicine, 676 St Clair Ave, Suite 650, Chicago, IL 60611 (E-mail: abharat@nm.org).

J Thorac Cardiovasc Surg 2017;154:785-6

$0022-5223 / \$ 36.00$

Copyright (c) 2017 by The American Association for Thoracic Surgery

http://dx.doi.org/10.1016/j.jtcvs.2017.04.075

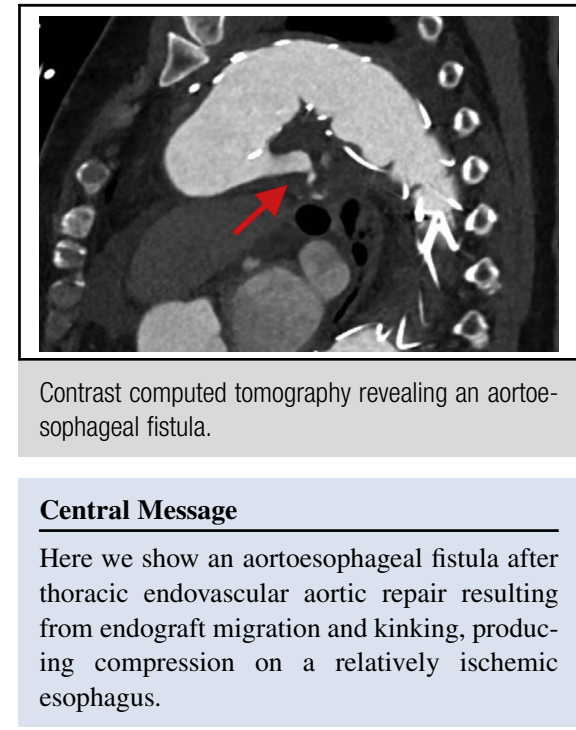

See Editorial Commentary page 787.
Thoracic endovascular aortic repair (TEVAR) is becoming the preferred treatment for thoracic aortic aneurysms. ${ }^{1,2}$ Aortoesophageal fistula is a rare, life-threatening complication following TEVAR. ${ }^{3}$ Here we present a 78-year-old female who developed hematemesis 2.5 years after TEVAR. Endoscopy revealed a 2-cm esophageal ulcer with endograft protruding into the lumen (Figure 1). A contrast computed tomography (CT) scan revealed a proximal type IA endoleak (Figures 2 and 3) with distal endograft migration (Figure 3) and kinking (Figures 4 and E1).

We hypothesize that migration and kinking of the endograft produced compression on a potentially malperfused esophagus from TEVAR coverage of its feeding arterial branches, ${ }^{4}$ leading to necrosis and subsequent creation of the aortoesophageal fistula. The patient underwent

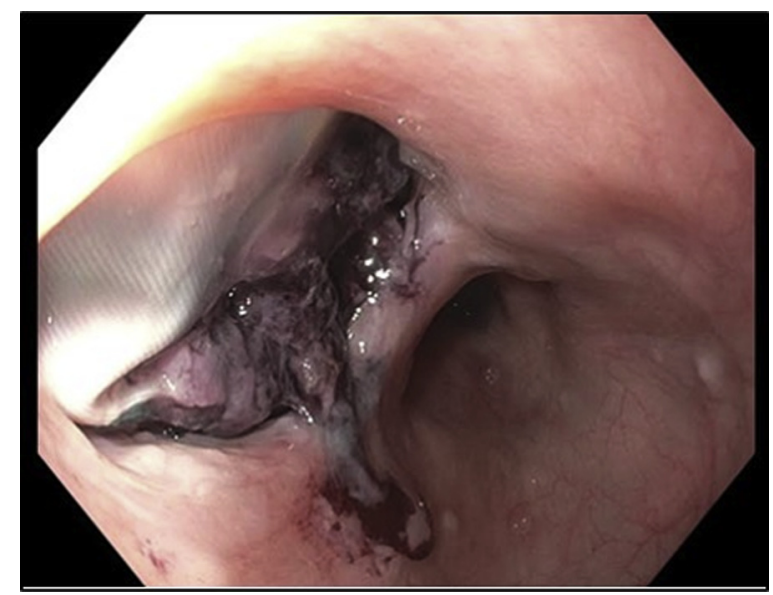

FIGURE 1. Endoscopy showing endograft protruding into the esophageal lumen. proximal endograft extension to the level of the innominate artery after a right-to-left carotid-carotid bypass. An esophageal stent was placed (Figure E2), and interval esophagectomy, retrosternal gastric tube reconstruction, and interposition of latissimus dorsi at the esophagoaortic interface were planned. This approach was based on previous reports of successful surgical intervention.

The patient declined esophagectomy, however, and has remained on moxifloxacin and fluconazole therapy indefinitely for graft infection prophylaxis. She was alive and asymptomatic 6 months later.

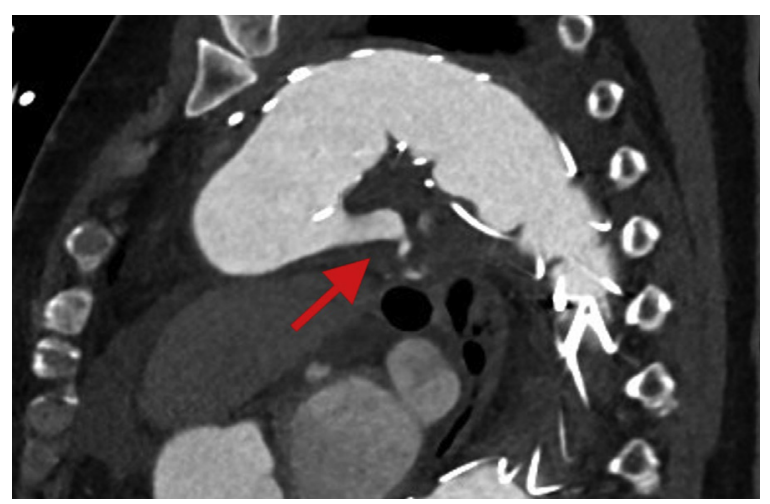

FIGURE 2. Contrast computed tomography revealing a type IA endoleak (arrow). 


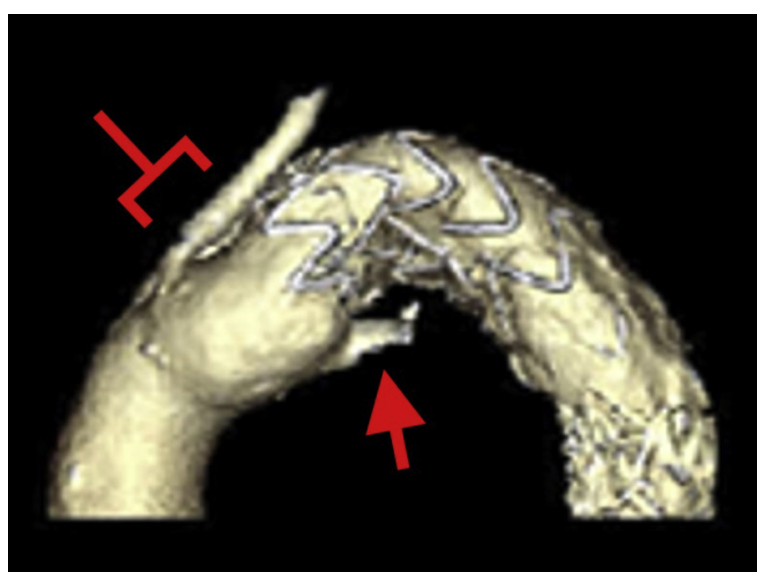

FIGURE 3. Computed tomography reconstruction indicating the type IA endoleak (arrow) and distal endograft migration (bracket).

\section{References}

1. Biancari F, Mariscalco G, Mariani S, Saari P, Satta J, Juvonen T. Endovascular treatment of degenerative aneurysms involving only the descending thoracic aorta: systematic review and meta-analysis. J Endovasc Ther. 2016; 23:387-92.

2. Scali ST, Goodney PP, Walsh DB, Travis LL, Nolan BW, Goodman DC, et al. National trends and regional variation of open and endovascular repair of thoracic and thoracoabdominal aneurysms in contemporary practice. J Vasc Surg. 2011;53: 1499-505.

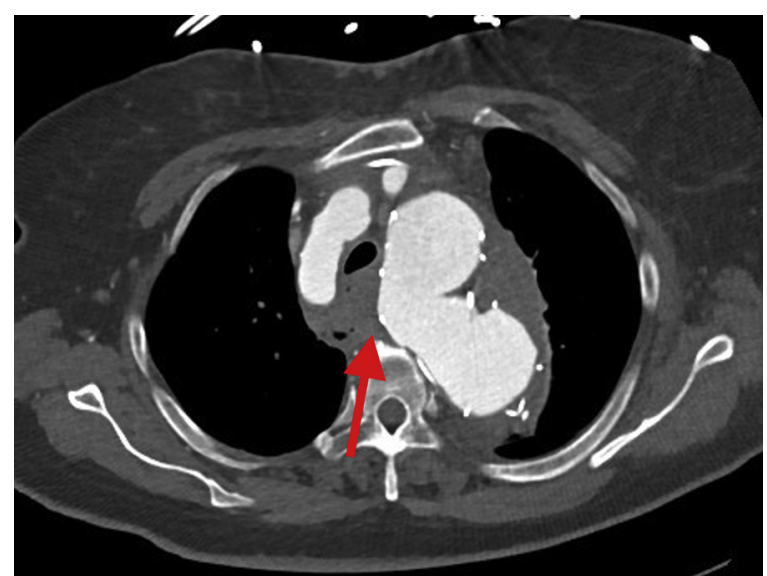

FIGURE 4. Computed tomography scan revealing a kinked endograft compressing the adjacent esophagus (arrow).

3. Eggebrecht H, Mehta RH, Dechene A, Tsagakis K, Kuhl H, Huptas S, et al. Aortoesophageal fistula after thoracic aortic stent-graft placement: a rare but catastrophic complication of a novel emerging technique. JACC Cardiovasc Interv. 2009;2:570-6.

4. Porcu P, Chavanon O, Sessa C, Thony F, Aubert A, Blin D. Esophageal fistula after endovascular treatment in a type B aortic dissection of the descending thoracic aorta. J Vasc Surg. 2005;41:708-11.

5. Canaud L, Ozdemir BA, Bee WW, Bahia S, Holt P, Thompson M. Thoracic endovascular aortic repair in management of aortoesophageal fistulas. J Vasc Surg. 2014;59:248-54. 


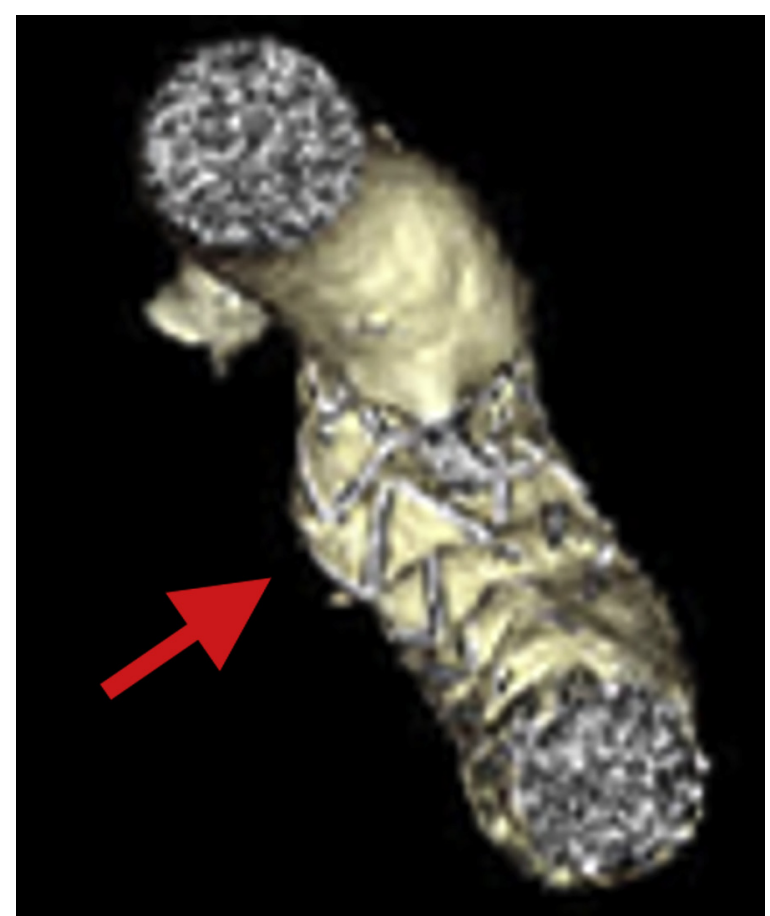

FIGURE E1. Computed tomography reconstruction revealing the kinked endograft.

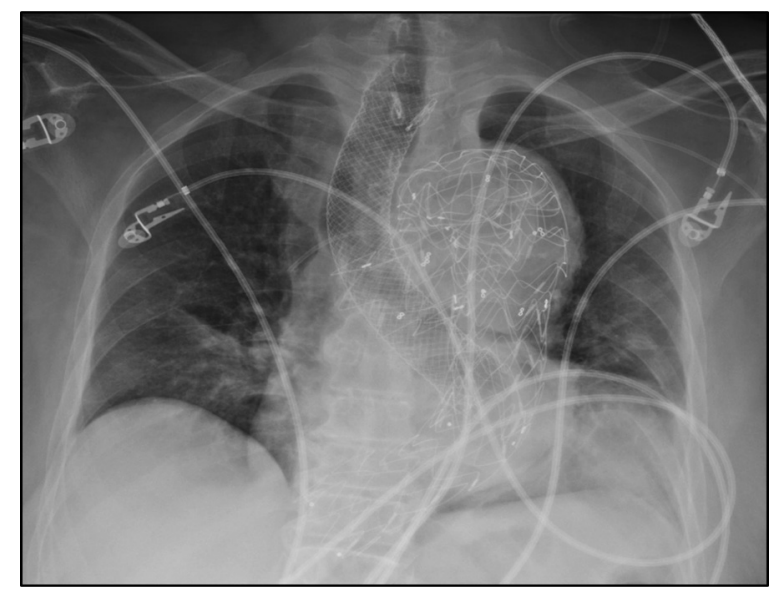

FIGURE E2. Computed tomography scan showing the aortic endograft and esophageal stent. 